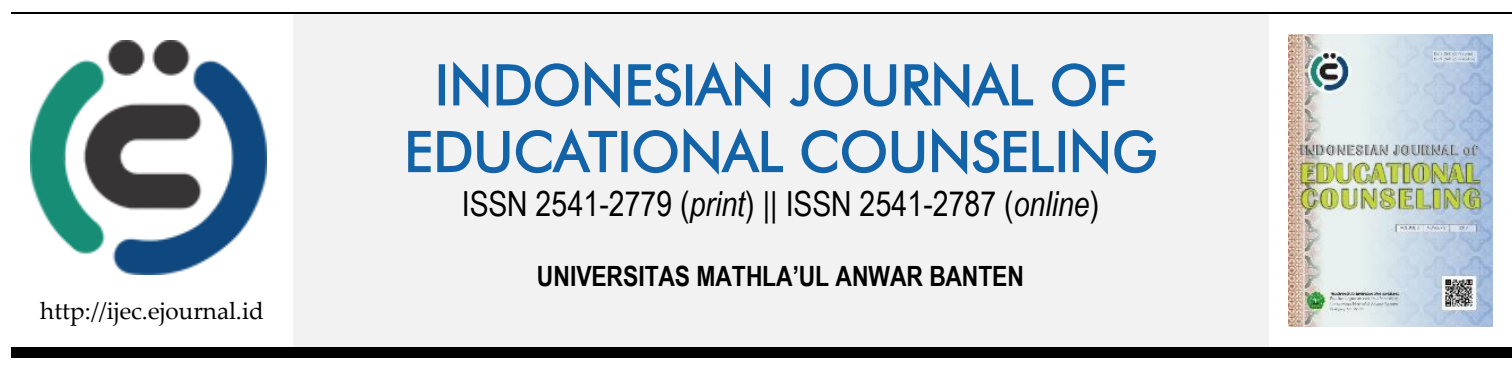

Research Based Article

\title{
Konseling Daring bagi Mahasiswa Universitas Sebelas Maret, Surakarta, Indonesia
}

\author{
Siti Sutarmi Fadhilah ${ }^{1}$, Agus Tri Susilo², Indriyana Rachmawati ${ }^{3}$ \\ 1, 2,3 Universitas Sebelas Maret
}

\begin{tabular}{|c|c|}
\hline Article History & ABSTRACT \\
\hline $\begin{array}{l}\text { Received: } 25.03 .2019 \\
\text { Received in revised form: } \\
01.04 .2019 \\
\text { Accepted: } 10.04 .2019 \\
\text { Available online: } 05.08 .2019\end{array}$ & $\begin{array}{l}\text { ONLINE COUNSELING FOR STUDENTS OF UNIVERSITAS SEBELAS } \\
\text { MARET, SURAKARTA, INDONESIA. The industrial revolution } 4.0 \text { resulted in } \\
\text { disruptive changes that affected human life. Likewise, the students of Sebelas } \\
\text { Maret University (UNS) in fulfilling their academic, personal, social, and career } \\
\text { development assignments, also often demanded independence in this } \\
\text { disruption era. As the third rank university in Indonesia, according to UniRank } \\
\text { 4ICU rating agency, UNS needs to respond to this in order to be able to facilitate } \\
\text { the task of developing students from the psychological side. Facilitation that } \\
\text { can be done is by providing online counseling services for students. This study } \\
\text { aims to describe the level of UNS student needs as initial data in compiling } \\
\text { online counseling services. The subjects of this study were } 544 \text { students from } \\
\text { ten faculties in the UNS that were randomly determined. The results of the } \\
\text { analysis showed that the needs of student counseling services included six } \\
\text { problem areas namely: personal-social ( } 81 \% \text { ), academic (76\%), career ( } 82 \%) \text {, } \\
\text { premarital ( } 75 \% \text { ), traumatic ( } 71 \% \text { ), and multicultural ( } 81 \%) \text {. The results of this } \\
\text { study indicate that the level of need for online counseling services for UNS } \\
\text { students is quite high. These results need to be followed up with the } \\
\text { development of an android-based online counseling service platform in order } \\
\text { to improve the quality of psychological services of UNS students. }\end{array}$ \\
\hline
\end{tabular}

DOI: $10.30653 / 001.201933 .111$

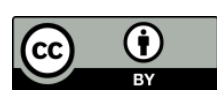

This is an open access article distributed under the terms of the Creative Commons Attribution 4.0 International License, which permits unrestricted use, distribution, and reproduction in any medium, provided the original work is properly cited. (c) 2019 Siti Sutarmi Fadhilah, Agus Tri Susilo, Indriyana Rachmawati.

\section{PENDAHULUAN}

Sejumlah temuan studi empiris memperlihatkan betapa layanan konseling di lingkungan perguruan tinggi sangat dibutuhkan keberadaannya sebagai unsur terpadu dalam keseluruhan program pendidikan khususnya yang berkenaan dengan peningkatan mutu dan relevansi pendidikan di perguruan tinggi. Konteks tersebut sejalan dengan pendapat Patterson (1980) mengungkapkan bahwa: “...education is concerned with development of thewhole child and not his intellect alone, attention must given toindividual 
differences in otherareas as well. Counseling develop on supplement to instruction, directed to the needs ofindividual students". Hal ini menunjukkan bahwa salah satu tujuan keberadaan layanan konseling di perguruan tinggi adalah membantu mahasiswa mencapai perkembangan diri secara optimal dalam bidang pribadi-sosial, akademik, karier ditambah dengan permasalahan multikultural, pranikah dan peristiwa atau kejadian yang menimbulkan trauma guna mengupayakan peningkatan efesiensi, kualitas serta produktivitas pendidikan tinggi.

Hasil kajian Hopkinson (2018) menggambarkan bahwa rendahnya kualitas dan produktivitas perguruan tinggi salah satunya disebabkan karena banyaknya permasalahan studi dan angka putus kuliah, terdapat sejumlah hambatan yang bersumber dari adaptasi diri dan gangguan sosioemosional, serta rendahnya motivasi mahasiswa menjadi suatu alasan pentingnya konseling di perguruan tinggi.

Selanjutnya Karen McKenzie (2015, pp. 284-288) mengemukakan bahwa tujuan umum layanan konseling diperguruan tinggi adalah sebagai upaya membantu memberikan kemudahan dan kelancaran mahasiswa dalam mencapai tugas-tugas perkembangannya, melalui upaya pengembangan kemampuan mahasiswa dalam mengambil keputusan secara mandiri, mempertautkan kepentingan individu dengan tuntutan sosial, dan menyelaraskan potensi mahasiswa dengan kemungkinan pekerjaan dan kariernya di masa mendatang. Tujuan-tujuan layanan konseling di atas menggambarkan bahwa belajar diperguruan tinggi menuntut berbagai kemampuan yang harus dimiliki mahasiswa dalam studinya. Karena sejatinya mahasiswa dituntut untuk lebih banyak belajar sendiri.

Pada konteks tersebut, Dahlan (1988, pp. 26-27) mengatakan bahwa karakteristik utama belajar di perguruan tinggi adalah kemandirian. Mahasiswa dituntut untuk lebih banyak belajar sendiri, mencari sumber belajar dan buku-buku sendiri, tanpa banyak diatur, diawasi, dan dikendalikan oleh dosen-dosennya. Untuk itu mahasiswa harus siap mental menghadapi kesulitan dan hambatan dalam belajar. Dengan kata lain mahasiswa dituntut mandiri untuk berolah fikir, berolah rasa, dan berkemauan. Berangkat dari sejumlah uraian di atas dapat dipahami bahwa layanan konseling di perguruan tinggi bertujuan membantu mahasiswa mengiringi proses perkembangannya melewati masamasa belajar dan menuntut ilmu di perguruan tinggi sehinggaterhindar dari berbagai kesulitan dan hambatan, dapat menyelesaikan masalahnya sendiri baikmasalah akademik maupun nonakademik, mampu menumbuh-kembangkan dirinya secara optimal, mampu mengaktualisasikan diri serta dapat mengambil tanggung jawab terhadap dirinya sendiri.

Proses pemenuhan tugas-tugas perkembangan yang dibutuhkan mahasiswa nampaknya perlu direspon secara komprehensif oleh para pendidik, pada konteks ini adalah dosen pada umumnya, khususnya adalah dosen bimbingan dan konseling di perguruan tinggi. Sebagai perguruan tinggi peringkat tiga di Indonesia versi lembaga pemeringkat 4ICU Uni Rank, UNS perlu merespon hal ini agar mampu memfasilitasi tugas perkembangan mahasiswa dari sisi psikologis. Fasilitasi yang bisa dilakukan yaitu dengan menyediakan layanan konseling daring bagi mahasiswa. Universitas Sebelas Maret memiliki 10 Fakultas dan terdiri dari beberapa Program Studi di dalamnya. Secara kuantitas, menunjukkan bahwa rasio dosen dan mahasiswa khususnya dalam pelayanan konseling bagi mahasiswa di Perguruan Tinggi sangatlah tidak ideal. Pelayanan secara 
konvensional layaknya kegiatan bimbingan dan konseling di sekolah dasar dan menengah hampir bisa dipastikan tidak akan bisa dipenuhi. Maka, di era revolusi industri $4.0 \mathrm{ini}$, konselor harus mampu memberikan customer satisfaction tanpa mengurangi kualitas dengan melalui layanan cybercounseling atau pelayanan konseling secara daring/online.

Kajian tersebut di atas akhirnya merumuskan tujuan yang diharapkan dari penelitian ini yaitu untuk mendiskripsikan tingkat kebutuhan mahasiswa UNS sebagai data awal dalam menyusun layanan konseling daring/online. Implikasinya adalah memberikan sumbangan pikiran secara teoritis dan praktis bahwa eksistensi layanan konseling di Perguruan Tinggi sangatlah dibutuhkan. Mahasiswa membutuhkan layanan konseling terkait hal-hal yang berkaitan dengan masalah akademik maupun non akademik.

\section{METODE}

Penelitian menggunakan pendekatan kuantitatif dengan jenis survey diskriptif. Jumlah subjek dalam studi sebanyak 544 mahasiswa UNS semester 1-5 dari sepuluh Fakultas yaitu Fakultas Keguruan dan Ilmu Pendidikan (FKIP), Fakultas Ilmu Budaya (FIB), Fakultas Matematika dan Ilmu Pengetahuan Alam (FMIPA), Fakultas Ilmu Sosial dan Politik (FISIP), Fakultas Pertanian (FP), Fakultas Seni Rupa dan Desain (FSRD), Fakultas Ekonomi dan Bisnis (FEB), Fakultas Hukum (FH), Fakultas Teknik (FT), dan Fakultas Kedokteran (FK). Subjek dalam penelitian ini ditentukan melalui teknik simple random sampling. Pengumpulan data menggunakan instrumen tingkat kebutuhan mahasiswa. Teknik analisis data yang digunakan analisis statistik deskriptif.

\section{HASIL DAN PEMBAHASAN}

Hasil analisis statistik diskriptif menunjukkan bahwa rata-rata $78 \%$ mahasiswa membutuhkan layanan konseling daring guna membantu permasalahan yang sedang dihadapi selama proses belajar di perguruan tinggi. Tingkat kebutuhan layanan konseling mahasiswa UNS meliputi enam bidang permasalahan yaitu: pribadi-sosial (81\%), akademik $(76 \%)$, karier $(82 \%)$, pranikah $(75 \%)$, traumatik $(71 \%)$ dan mutikultural $(81 \%)$ yang tertuang dalam instrument need assessment mewakili permasalahan-permasalahan yang sudah disesuaikan dengan tugas-tugas perkembangan masa remaja akhir. Bisa diperjelas dengan diagram di Gambar 1.

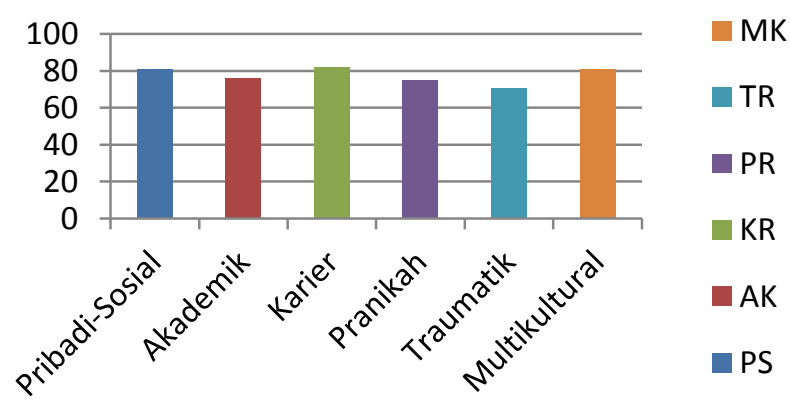

Gambar 1. Tingkat Kebutuhan Mahasiswa 
Setiap bidang permasalahan dirumuskan secara proporsional topik yang akan dipilih oleh mahasiswa. Selanjutnya dipilih empat kebutuhan teratas sesuai masingmasing bidang. Hasilnya dapat dijelaskan pada Tabel 1.

Tabel 1. Tingkat Kebutuhan Permasalahan Pribadi-Sosial

\begin{tabular}{lll}
\hline No. & Jenis Kebutuhan & Presentase \\
\hline 1 & Pengembangan keterampilan berfikir positif & $84 \%$ \\
\hline 2 & Pengembangan keterampilan mengevaluasi diri & $86 \%$ \\
\hline 3 & Peningkatan disiplin diri & $89 \%$ \\
\hline 4 & Pemahaman bahaya narkoba, rokok dan alkohol & $88 \%$ \\
\hline
\end{tabular}

Berkaitan dengan permasalahan pribadi-sosial, kebutuhan mahasiswa antara lain untuk memahami, menerima, mengarahkan, mengambil keputusan, dan merealisasikan keputusannya secara bertanggung jawab tentang perkembangan aspek pribadi sosialnya, sehingga dapat mencapai perkembangan yang optimal dan mencapai kemandirian.

Tabel 2. Tingkat Kebutuhan Permasalahan Akademik

\begin{tabular}{lll}
\hline No. & Jenis Kebutuhan & Presentase \\
\hline 1 & Pengembangan keterampilan berdiskusi di kelas & $78 \%$ \\
\hline 2 & Mencari referensi tugas di internet & $82 \%$ \\
\hline 3 & Eksplorasi gaya belajar & $84 \%$ \\
\hline 4 & Keterampilan fokus saat belajar & $81 \%$ \\
\hline
\end{tabular}

Kebutuhan berkaitan dengan bidang akademik mahasiswa antara lain adalah mengenali potensi diri untuk belajar dan berdiskusi, memiliki sikap, keterampilan belajar dan mencari referensi, terampil merencanakan pendidikan, memiliki kesiapan menghadapi ujian, memiliki kebiasaan belajar teratur sesuai gaya belajar dan mencapai hasil belajar secara optimal sehingga dapat mencapai kesuksesan.

Tabel 3. Tingkat Kebutuhan Permasalahan Karier

\begin{tabular}{lll}
\hline No. & Jenis Kebutuhan & Presentase \\
\hline 1 & Keterampilan merencanakan karier masa depan & $86 \%$ \\
\hline 2 & Pengembangan minat bekerja seteah lulus kuliah & $84 \%$ \\
\hline 3 & Keterampilan memilih karier setelah lulus sarjana & $88 \%$ \\
\hline 4 & Mencari informasi pekerjaan & $84 \%$ \\
\hline
\end{tabular}

Kebutuhan akan permasalahan karier diantaranya untuk memahami bakat minat, eksplorasi, perencanaan dan pengambilan keputusan karier sepanjang rentang hidupnya secara rasional dan realistis berdasar informasi potensi diri dan melihat kesempatan yang tersedia di lingkungan. 
Tabel 4. Tingkat Kebutuhan Permasalahan Pranikah

\begin{tabular}{lll}
\hline No. & Jenis Kebutuhan & Presentase \\
\hline 1 & Sikap positif atau respect terhadap diri sendiri dan pasangan & $91 \%$ \\
\hline 2 & Keterampilan pengelolaan perasaan terhadap lawan jenis & $85 \%$ \\
\hline 3 & $\begin{array}{l}\text { Keterampilan membangun komitmen yang kuat dalam } \\
\text { membina hubungan bersama pasangan }\end{array}$ & $78 \%$ \\
\hline 4 & Keterampilan memahami hakikat dan tujuan pernikahan & $78 \%$ \\
\hline
\end{tabular}

Secara umum, mengenali permasalahan pranikah bagi mahasiswa bertujuan agar individu mempersiapkan dan mengembangkan seluruh potensi dan kekuatan yang dimilikinya dalam memasuki jenjang pernikahan, penyesuaian diri dengan lingkungan keluarga dan masyarakat serta mengatasi hambatan dan kesulitan meng-hadapi jenjang pernikahan.

Tabel 5. Tingkat Kebutuhan Permasalahan Multikultural

\begin{tabular}{lll}
\hline No. & Jenis Kebutuhan & Presentase \\
\hline 1 & Keterampilan menjalin persahabatan multikultural & $89 \%$ \\
\hline 2 & Kemampuan toleransi antar umat beragama & $89 \%$ \\
\hline 3 & Menghargai perbedaan dalam pergaulan & $87 \%$ \\
\hline 4 & Keterampilan memahami hakikat dan tujuan pernikahan & $86 \%$ \\
\hline
\end{tabular}

Kesadaran nilai multikultral menjadi hal yang penting. Hansen (2003) menyatakan kemajuan dalam penggunaan teknologi, perhatian terhadap permasalahan multikultural berpotensi untuk memperkaya kontribusi profesi konseling karier dalam pengambangan individu dan kesetaraan sosial. Artinya pemahaman tentang multikultural pada saat ini akan berdampak pada kehidupan karier, pribadi, dan sosial individu. Mengingat pada akhirnya mahasiswa akan mulai memikirkan tentang arah karier ke depan, maka pemahamana akan perbedanaan budaya dan permasalahan yang mengikuti, perlu dipahami oleh mereka Permasalahan multikultural berhubungan dengan perlunya pemahaman akan adanya eksistensi manusia secara utuh. Memahami manusia dengan keberadaanya perlu menyadari bahwa manusia memiliki kemerdekaan yang perlu dihargai. Untuk itu, semua yang ada dalam diri manusia penting untuk dipahami ketika berinteraksi dengan manusia lainnya. Cara berpikir demikian akan memberikan konsekuensi munculnya perilaku interaktif yang positif. Perilaku tersebut seperti misalnya penghargaan terhadap orang lain, kesediaan untuk bekerjasama, tidak menghakimi orang lain, empati dan sebagainya. Perilaku moral yang demikian tampaknya perlu dijaga dan dilestarikan.

Tabel 6. Tingkat Kebutuhan Permasalahan Akibat Peristiwa Traumatik

\begin{tabular}{lll}
\hline No. & Jenis Kebutuhan & Presentase \\
\hline 1 & Keterampilan menghadapi bullying (fisik maupun cyber) & $78 \%$ \\
\hline 2 & Keterampilan mengendalikan ketakutan terhadap sesuatu (phobia) & $81 \%$ \\
\hline 3 & $\begin{array}{l}\text { Keterampilan merespon kegagalan yang mendalam dalam } \\
\text { pekerjaan atau event besar }\end{array}$ & \\
\hline 4 & $\begin{array}{l}\text { Keterampilan mengelola stress saat mempersiapkan maupun } \\
\text { menghadapi hasil ujian }\end{array}$ & $81 \%$ \\
\hline
\end{tabular}


Keberagaman peristiwa dan pengalaman krisis dan traumatik, selain akan mengganggu kondisi fisik dan lingkungan, juga mengganggu ketahanan fungsi mental manusia yang mengalaminya, baik secara langsung maupun tidak langsung dalam waktu yang singkat dan jangka panjang.

Layak kiranya bahwa kebutuhan-kebutuhan permasalahan hasil kajian empiris tersebut untuk ditindaklanjuti dengan pemberian solusi yang tepat. Internet menjadi arena terbaru di mana layanan konseling tersedia untuk berbagai masalah, seperti pribadi-sosial, akademik, karier, pranikah, traumatik dan mutikultural (Lewis dan Coursol, 2007). Pengembangan sebuah aplikasi konseling berbasis online kiranya tepat sebagai jawaban atas permasalahan yang muncul di UNS. Dikaitkan dengan perkembangan teknologi yang mulai memasuki era industri 4.0, di nama masa kini dikenal dengan adanya generasi milenial, maka teknologi menjadi hal yang dekat dengan anak masa kini. Maples dan Han (2008) menyatakan keistimewaan yang unik dari generasi milenial adalah mereka tumbuh dalam masa di mana teknologi berkembang secara tepat. Ini mengindikasikan bahwa generasi milenial ramah akan teknologi yang terus berkembang karena tidak ingin ketertinggalan zaman.

Konselor perlu untuk menanggapi hal ini dengan memanfaatkan teknologi untuk pemberian layanan. ASCA (2016) menyatakan bahwa konselr sebagai bagian dari masyarakat digital perlu untuk memilih dan menggunakan teknologi dan aplikasi perangkat lunak dalam peningkatan layanan akademik, karier, dan perkembangan sosialemosional. Artinya konselor berhak untuk menggunakan teknologi dan aplikasi perangkat lunak untuk membantu siswa mengentaskan dan menangani permasalahan mahasiswa. Gibson (2008) menyebutkan pelayanan ini dilakukan oleh konselor untuk memberikan kenyamanan bantuan yang dibutuhkan konseli ketika menghadapi masalah dan tidak mungkin bertemu secara face to face. Hal ini diperkuat oleh pendapat dari Centore dan Milacci (2008) bahwa hubungan konseling telah mengalami perkembangan, di mana secara historis hubungan konseling dilakukan melalui serangkaian komunikasi langsung antara konselor dan klien, namun pada saat ini modalitas telepon dan online memberikan tawaran alternatif lainnya untuk membentuk hubungan tersebut.

Proses konseling daring/online bukanlah sebuah proses yang sederhana. Diperlukan kemampuan pendukung lain selain ketrampilan dasar konseling, sebagaimana yang dikemukan oleh Koutsonika (2009): "Online Counseling is not a simple process. On the contrary is a complex process with a considerable number of different and challenging issues characterizing it. Ethical issues, Technological issues, Counselors' educational background and skills especially for online counseling issues, Clients' issues, Legal issues and, finally, Business and Management issues". Ada beberapa media konseling daring/ online yang dapat digunakan antara lain; website, email, telephone, chat, mobile learning application, dan video conference. Arifpurnamayana (2012) menyatakan bahwa mobile learning dapat didefinisikan sebagai salah satu fasilitas atau layanan yang memberikan informasi elektronik secara umum kepada pembelajar dan content yang edukasional yang membantu mencapai pengetahuan tanpa mempersalahkan lokasi dan waktu.

Mobile learning merupakan salah satu metode pembelajaran baru yang memaksimalkan dalam penggunaan teknologi perangkat mobile atau smartphone. Pengembangan media mobile learning harus dikembangkan semenarik mungkin agar 
motivasi belajar siswa dapat meningkat. Smartphone bekerja berdasarkan sistem operasi antara lain Android, iOS, Windows Phone, dll. Huda (2013, pp. 1-3) menjelaskan bahwa android merupakan sebuah sistem operasi berbasis Linux yang didesain khusus untuk perangkat bergerak seperti smartphone dan tablet. Dari data beberapa tahun terakhir, android mempunyai jumlah pengguna paling besar karena mudah digunakan dan memiliki beberapa keunggulan dalam sistem operasinya. Android memiliki berbagai fitur yang yang dapat dimanfaatkan guna menunjang dalam penggunaannya sebagai mobile learning. Hal ini mendukung riset yang menunjukkan bahwa hampir semua mahasiswa di lingkungan UNS sudah memiliki dan mampu mengoperasikan handphone berbasis android.

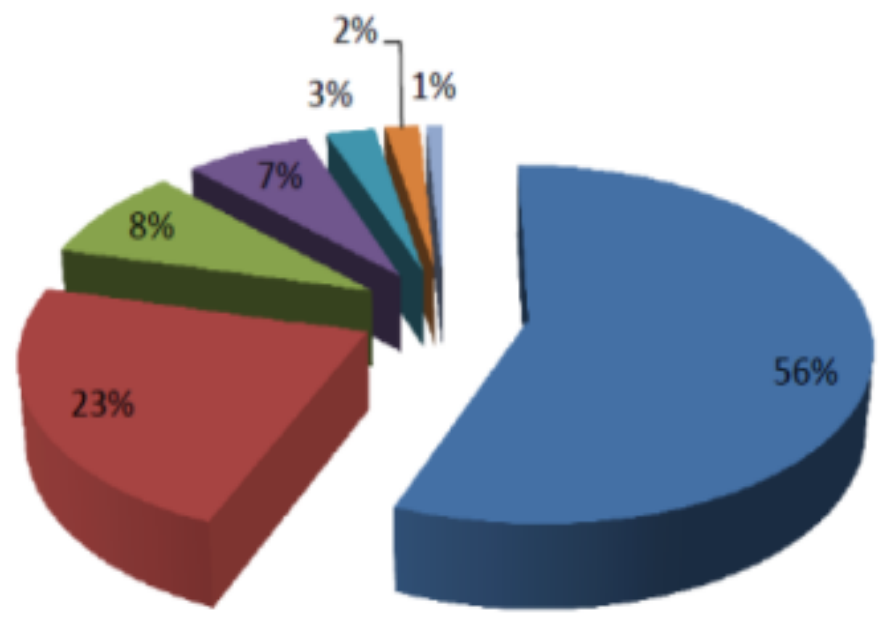

\author{
android \\ -iOS \\ nymbian \\ Research InMotion \\ Bada \\ Microsoft \\ Others
}

Gambar 2. Diagram Market Share OS Smartphone

Review atas state of the art dan inovasi yang telah ada sebelumnya oleh Maulana (2017) tentang "development of mobile learning based learning media with android platform of occupational health and safety (ohs) materials for students of electrical power study program of vocational high schools". Risetini merupakan penelitian dan pengembangan (research and development) yang menghasilkan produk yaitu media pembelajaran berbasis mobile learning dengan platform android materi keselamatan kesehatan kerja dan lingkungan hidup (K3LH) pada program studi ketenagalistrikan untuk siswa SMK. Hasilnya, penilaian ahli mengenai materi memperoleh persentase skor $87.31 \%$, hasil penilaian ahli berkaitan dengan media memperoleh persentase skor $80.48 \%$, dan hasil penilaian uji pengguna mendapatkan skor $80.69 \%$. Artinya pengembangan media pembelajaran berbasis mobile learning dengan platform android ini bisa diaplikasikan dalam proses pembelajaran. Riset lainnya oleh Ansharifur (2017) tentang "pengembangan aplikasi MLearning untuk platform Android" menjadi rujukan proses pembelajaran berbasis elearning yang sangat dibutuhkan oleh peserta didik saat ini.

Pada akhirnya, terdapat hal penting yang perlu diperhatikan dalam pemanfaat media online atau teknologi untuk pemberian layanan bimbingan dan konseling, yaitu kredensial. Harris-Bowlsbey dan Sampson (2005) menyatakan kredesial konselor dalam memberikan layanan jarak jauh berupa layanan online berupa sertifikat sangat 
dibutuhkan untuk membantu meyakinkan konseli bahwa konselor telah memenuhi kriteria minimun yang diperlukan dalam melaksanakan praktik yang kompeten, seperti Distance Certified Counselor (DCC). Kriteria yang dimaksudkan dapat berupa memiliki gelar master dalam bidang konseling maupun bidang terkait yang tepat, berhasil menyelesaikan pelatihan konselor jarak jauh, dan memiliki status sebagai konselor bersertifikat nasional. Selain itu, konselor profesional yang menggunakan konseling online perlu untuk memperhatikan tentang efektivitas dan keamanan dari data konseli yang diperoleh dengan mematuhi standar ACA dan berkonsultasi dengan dewan lisensi tentang peraturan yang berlaku dalam penggunaan konseling online (Heinlen dkk., 2003).

Berbagai hasil riset sebelumnya menjadi pijakan peneliti merekomendasikan pengembangan layanan konseling daring/online berbasis android untuk membantu kebutuhan-kebutuhan bagi mahasiswa UNS. Layanan konseling online ini diharapkan mampu menjadi pilihan mahasiswa dalam konsultasi layanan bimbingan dan konseling secara cyber/online untuk membantu mengiringi proses perkembangannya melewati masa-masa belajar dan menuntut ilmu di perguruan tinggi sehingga terhindar dari berbagai kesulitan dan hambatan, dapat menyelesaikan masalahnya sendiri baik masalah akademik maupun nonakademik, mampu menumbuhkembangkan dirinya secara optimal, mampu mengaktualisasikan diri serta dapat mengambil tanggung jawab terhadapdirinya sendiri mengenai arah karier di masa depan.

\section{SIMPULAN}

Hasil penelitian menunjukkan bahwa tingkat kebutuhan layanan konseling mahasiswa UNS tergolong tinggi, meliputi enam bidang permasalahan yaitu: pribadisosial $(81 \%)$, akademik $(76 \%)$, karier $(82 \%)$, pranikah $(75 \%)$, traumatik $(71 \%)$ dan mutikultural(81\%). Hasil tersebut memberikan sumbangan pikiran secara teoritis dan praktis bahwa eksistensi layanan konseling di Perguruan Tinggi sangatlah dibutuhkan. Mahasiswa membutuhkan bimbingan terkait hal-hal yang berkaitan dengan masalah akademik maupun non akademik, yang akhirnya nanti berkaitan dengan arah perencanaan karier di masa depan. Untuk itu, layanan konseling harus mampu menjangkau setiap lapisan mahasiswa, tidak terkhusus pada satu Fakultas saja, akan tetapi semua mahasiswa di lingkungan UNS melalui pengembangan platform layanan konseling daring berbasis android yang bisa diakses mahasiswa dari mana saja dan kapan saja tanpa harus terbatas ruang dan waktu.

\section{REFERENSI}

Ansharifur. (2017). Pengembangan aplikasi m-learning untuk platform android. Tesis pada Program Pascasarjana UPI Bandung (tidak diterbitkan).

Arifpurnamayana, M. I. (2012). Rancangan dan pembuatan mobile learning berbasis android. Jakarta: Universitas Gunadarma. 
Association School Counselor Association. (2016). ASCA ethical standards for school counselors. Alexandria, VA: Association School Counselor Association.

Centore, A., \& Milacci, F. (2008). A study of mental health counselors' use of and perspectives on distance counseling. Journal of Mental Health Counseling, 30(3), 267282.

Dahlan, M. D. (1988) Posisi bimbingan dan penyuluhan dalam kerangka ılmu pendidikan.Pidato Pengukuhan Jabatan Guru Besar dalam Pendidikan. Bandung: FIP IKIP.

Gibson, R. L., \& Mitchell, M. H. (2008). Introduction to counseling and guidance. New York: Macmillan Publisher.

Hansen, S. S. (2003). Career counselors as advocates and change agents for equality. The Career Development Quarterly, 52(1), 43-53.

Harris-Bowlsbey, J., \& Sampson Jr, J. P. (2005). Use of technology in delivering career services worldwide. The Career Development Quarterly, 54(1), 48-56.

Heinlen, K. T., Welfel, E. R., Richmond, E. N., \& Rak, C. F. (2003). The scope of webcounseling: A survey of services and compliance with NBCC standards for the ethical practice of webcounseling. Journal of Counseling $\mathcal{E}$ Development, 81(1), 61-69.

Hopkinson, MS,D. (2018). International school of Paris university counseling handbook. Paris: Paris University.

Huda, A.A. (2013). LIVECODING! 9 aplikasi android buatan sendiri. Yogyakarta: Andi Offset.

McKenzie, K., Murray, K. R., Murray, A. L., \& Richelieu, M. (2015). The effectiveness of university counselling for students with academic issues. Counselling and Psychotherapy Research, 15(4), 284-288.

Koutsonika, H. (2009). E-Counseling: the new modality. Online Career Counseling-a challenging opportunity for greek tertiary education. In Proceedings of the WebSci'09: Society On-Line, 18-20 March 2009, Athens, Greece.

Lewis, J., \& Coursol, D. (2007). Addressing career issues online: Perceptions of counselor education professionals. Journal of Employment Counseling, 44(4), 146-153.

Maples, M. F., \& Han, S. (2008). Cybercounseling in the United States and South Korea: Implications for counseling college students of the millennial generation and the networked generation. Journal of Counseling \& Development, 86(2), 178-183. 
INDONESIAN JOURNAL OF EDUCATIONAL COUNSELING 2019, 3(3), 283-292

Maulana, L. M. L. (2017). Pengembangan media pembelajaran berbasis mobile learning dengan platform android materi keselamatan kesehatan kerja dan lingkungan hidup (K3LH) pada program studi ketenagalistrikan untuk siswa sekolah menengah kejuruan. Jurnal Pendidikan Teknik Mekatronika, 7(2), 197-207.

Patterson, C.H. (1980). Theories of counseling and psychotherapy. New York: Harper \& Merril Prentice Hall. 